Rodrigo de Campos Costa, Delegado de Polícia Federal, especialista, mestre e doutorando em Direito Processual Penal pela PUC-SP

Área do Direito: Direito Processual Penal

Resumo: O presente artigo tem por finalidade discutir a teoria geral de provas, particularmente, a produção de provas em criminalidade organizada em conjunto com o princípio da proporcionalidade. Também analisa as principais provas utilizadas para o desmantelamento de organizações criminosas, como a interceptação telefônica, a infiltração de agentes e a delação premiada.

Palavras-Chave: teoria geral das provas, teoria da proporcionalidade, criminalidade organizada, interceptação telefônica, infiltração de agentes e delação premiada.

Sumário: 1. Introdução; 2. Teoria da Proporcionalidade, Razoabilidade e Prova Ilícita pro reo; 3. Escutas Telefônicas; 4 Infiltração de Agentes; 5. Ação Controlada; 6 Delação Premiada e Valoração da Prova.

Abstract: This article aims to discuss the general theory of evidence, particularly the production of evidence in organized crime in conjunction with the principle of proportionality. It also analyzes the main evidence used for the dismantling of criminal organizations, such as telephone interception, infiltration of agents and the awardwinning tipoff.

Keywords: general theory of evidence, proportionality theory, organized crime, telephone interception, infiltration of agents and informers rewarded.

\title{
Teoria Geral das Provas em Criminalidade Organizada.
}

\section{Introdução:}

Para que se firmem as premissas do tema proposto, se faz necessário estabelecer alguns conceitos eminentemente fundamentais acerca do conceito de prova, suas espécies e a finalidade do processo penal.

Por prova, genericamente falando, podemos tê-la como aquele dado ou substrato que permite fixar ou firmar a existência de um fato. 
Conforme preleciona MARCO ANTÔNIO MARQUES DA SILVA: “A prova é dado concreto e objetivo que leva o juiz a ciência sobre um fato, para que sobre ele seja feito um julgamento"".

A prova reconstrói um fato pretérito, de maneira que tenta permitir às partes visualizar, ainda que precariamente, a existência ou não de um fato, cuja natureza tenha interesse e pertinência com o objeto a ser julgado; demonstrar a existência ou inexistência de um fato consiste, analiticamente falando, a finalidade geral da prova.

O processo penal materializa o direito penal, um dos mais importantes ramos do direito, senão o mais importante, na medida em que tutela os bens jurídicos de maior valia para a convivência harmônica na sociedade. Nesse sentido, é importante analisar que o direito penal tem como elemento intimidador a pena, que pode chegar, em casos extremos, ao cerceamento da liberdade.

Considerando esse elemento intimidador - a pena - o processo penal é regido pelo princípio da verdade real ou material, isto é, orienta-se no sentido de descobrir a verdade efetiva dos fatos, diferentemente do processo civil, onde vige a verdade formal, o que significa dizer, basta ao julgador os elementos que são a ele apresentados para o julgamento do feito.

Ao materializar o direito penal, um dos resultados possíveis é o cerceamento da liberdade, um dos bens mais valiosos previstos no art. $5^{\circ}$ da Constituição Federal de 1988, à exceção da vida, portanto, deve o magistrado esgotar os meios probatórios necessários e disponíveis visando comprovar ou não a existência do fato submetido a julgamento, sob pena do cometimento de injustiça.

Nesse sentido, vale trazer à baila o que escreve VERA KAISER SANCHEZ KERR a respeito da verdade material enquanto finalidade do processo penal e sua impossibilidade de consecução integral: "Contudo, hodiernamente, entende-se que a verdade material é inalcançável, pois o que deve ser buscado é a verdade possível de ser atingida, a verdade processual"2.

Conquanto sua finalidade acima destacada, a coleta de prova, especialmente em seara penal, deve obedecer a um rito, a um conjunto de normas previamente estabelecidas em lei, sob pena de afronta ao princípio do devido processo legal e da vedação de provas ilícitas, conforme preceitua o art.5\% da Carta Magna.

\footnotetext{
${ }^{1}$ Código de Processo Penal Comentado, p.262.

${ }^{2}$ Provas no Processo Penal, Estudo Comparado, p.46. http://revistasapereaude.org/index.php/edicoes/ano-5-volume-2-setembro-2016 D.O.I: 10.20523/sapereaude-ano5-vol-2-pg-64-79
} 
A coleta de prova sem a necessária obediência às regras estabelecidas na legislação infraconstitucional acarreta na sua invalidade, vale dizer, será declarada como ilícita e retirada dos autos.

Em virtude dos fundamentos e objetivos do processo penal, o legislador nacional não estabeleceu quais são os meios de provas existentes no direito brasileiro, mas limitou-se a estabelecer regras gerais, orientadas no princípio da vedação de provas ilícitas, no contraditório, na ampla defesa, no devido processo legal e, especialmente, na dignidade da pessoa humana, para sua obtenção. Diante disso, a doutrina encarregou-se de definir e classificar as espécies de provas atuantes no direito processual penal, quais sejam, as provas típicas e atípicas, por típicas entendam-se as provas explicitamente previstas na legislação, sobretudo, no Código de Processo Penal e leis extravagantes; por atípicas aquelas que não se encontram previstas na legislação.

A respeito de tema tão importante, trazemos à análise o que escreve ANTONIO SCARANCE FERNANDES ${ }^{3}$ sobre a classificação das provas: “[...] a prova típica é aquela prevista e dotada de procedimento próprio para sua efetivação; a prova atípica, por conseguinte, é aquela que, prevista ou não, é destituída de procedimento para a sua produção."

Porquanto, é fundamental para o estudo do presente texto, identificarmos o novo conceito de prova após a reforma de Lei 11.690/2008, no qual o legislador, privilegiando os postulados da ampla defesa e do contraditório, deu nova redação ao art.155 do Código de Processo Penal, in verbis:

Art. 155. O juiz formará sua convicção pela livre apreciação da prova produzida em contraditório judicial, não podendo fundamentar sua decisão exclusivamente nos elementos informativos colhidos na investigação, ressalvadas as provas cautelares, não repetíveis e antecipadas.

Portanto, consoante a nova redação do dispositivo legal acima em destaque, considerar-se-á prova, apenas e tão somente, aquelas que forem produzidas sob crivo dos princípios do contraditório e da ampla defesa, à exceção das que forem impossíveis de serem repetidas.

\footnotetext{
${ }^{3}$ Ibidem, p. 15 .

http://revistasapereaude.org/index.php/edicoes/ano-5-volume-2-setembro-2016

D.O.I: 10.20523/sapereaude-ano5-vol-2-pg-64-79
} 
A título de exemplo, as provas testemunhais deverão obrigatoriamente ser repetidas em juízo, por outro lado, dados obtidos através do monitoramento telefônico serão submetidos ao contraditório diferido, uma vez que não podem ser repetidos.

Nesta linha, o processo penal contemporâneo encontra-se em uma fase extremamente sensível, isso porque a sociedade vem enfrentando o aumento desenfreado de todas as formas de criminalidade, especialmente, as de cunho organizado, seja com matiz violento ou não.

Esse aumento da criminalidade organizada vem exigindo uma reposta mais eficaz tanto do direito penal como do processo penal, entretanto, a criminalidade com matiz organizacional, com base piramidal ou de torres, com infiltração no poder público e etc., consiste em matéria de difícil comprovação, haja vista a dificuldade na obtenção de provas em um processo extremamente complexo e intrincado de demonstração de condutas.

A respeito da dificuldade na obtenção de provas relacionadas à criminalidade organizada, sobretudo a existência de redes de relacionamentos complexas, JOÃO PAULO BALTAZAR JÚNIOR ${ }^{4}$ assim disserta sobre o tema:

Os delitos de organizações criminosas, sejam elas de tipo violento ou empresarial, apresentam dificuldades probatórias se comparadas com a criminalidade tradicional. A prova em delitos de criminalidade organizada é fragmentária, dispersa, assemelha-se a um verdadeiro mosaico $[\ldots]$.

Para esse tipo de criminalidade os meios convencionais de provas já se mostraram deveras ineficientes, sendo necessário lançar mão de técnicas especiais de investigação, conhecidas popularmente como T.E.I., conforme ensina FAUSTO MARTIN DE SANCTIS ${ }^{5}$ :

As chamadas técnicas especiais de investigação são consideradas indispensáveis para o enfrentamento da criminalidade organizada e estão em consonância com as obrigações assumidas pelo Brasil, no campo internacional, por meio da Convenção Contra o Tráfico Ilícito de Entorpecentes e Substâncias Psicotrópicas (Convenção de Viena de 1988, artigo 11, itens 1,2 e 3), da Convenção das Nações Unidas contra

\footnotetext{
${ }^{4}$ Limites Constitucionais à Investigação. $O$ conflito entre o direito fundamental à segurança e o direto de liberdade no âmbito da investigação criminal, p.211

${ }^{5}$ Crime Organizado e Lavagem de Dinheiro, p.10 http://revistasapereaude.org/index.php/edicoes/ano-5-volume-2-setembro-2016 
o Crime Organizado Transnacional (Convenção da ONU de 2000, artigo 20) e da Convenção das Nações Unidas Contra a Corrupção (Convenção da ONU contra a corrupção de Mérida de 2003, artigo 50).

Entretanto, referidas técnicas especiais de investigação, em virtude de sua agressividade, ferem ou lesionam direitos e garantias individuais previstos na Carta Política de 1988, especialmente, a intimidade dos investigados e envolvidos direta ou indiretamente nesse tipo especial de criminalidade.

Assim, o binômio garantia e eficiência consiste na pedra fundamental do processo penal contemporâneo, sobretudo naqueles que têm como fundamento o Estado Democrático de Direito.

Como estabelecer o equilíbrio entre a prevalência de garantias fundamentais ao investigado, em despropósito de uma investigação eficiente, em benefício da sociedade, tão refém de atos criminosos e de barbáries das mais ignóbeis, consiste em tarefa das mais árduas.

O binômio - garantia e eficiência - deve sustentar-se equilibrado, sob pena de afronta ao Estado Democrático de Direito e o cometimento de enormes injustiças, seja em desfavor do investigado, seja em desfavor da própria sociedade, que já vivenciou regimes totalitários e ditatoriais nos quais eram suprimidas diversas garantias e direitos fundamentais, sob o manto da ilegítima proteção e manutenção da paz social.

ANTONIO SCARANCE FERNANDES ${ }^{6}$ assim se posiciona a respeito do tema:

Entende-se ser eficiente o processo que além de permitir uma eficiente persecução criminal, também possibilita uma eficiente atuação das normas de garantia. Assim, é dotado de eficiência o ordenamento formado por regras que permitam o equilíbrio entre o interesse do estado em punir autores de infrações penais e o interesse do acusado em se defender plenamente.

$[\ldots]$

Não se deve pender para os extremos de um hipergarantismo ou de uma repressão a todo custo.

Feito este escorço, passemos agora à análise dos tópicos delineados no título do presente artigo.

\footnotetext{
${ }^{6}$ O Equilíbrio na Repressão ao Crime Organizado, p.13.

http://revistasapereaude.org/index.php/edicoes/ano-5-volume-2-setembro-2016
}

D.O.I: 10.20523/sapereaude-ano5-vol-2-pg-64-79 


\section{Teorias da proporcionalidade, razoabilidade e prova ilícita pro reo;}

Façamos um recorte na teoria da proporcionalidade, pode parecer exaustivo, mas se faz necessário para que entendamos sobre quais premissas assentar-se-ão o presente texto acadêmico.

Nossa linha de pesquisa adotará como fundamento a Teoria da Proporcionalidade, aquela defendida por ROBERT ALEXY, em que pese o respeito que temos pela linha defesa sustentada por RONALD DWORKING, no entanto, entendemos que a teoria principiológica desenvolvida pelo jusfilósofo alemão se adapta melhor ao nosso ordenamento jurídico.

Porquanto, antes de adentrar na aplicação do princípio da proporcionalidade, é fundamental estabelecer o conceito de princípio e suas variantes, bem como quais sãos suas diferenças com as regras e por qual razão é invocado o princípio da proporcionalidade.

Primeiramente, deve-se ter em mente que tanto o princípio como a regra são espécies do gênero norma, no entanto, a despeito de serem do mesmo gênero, possuem diferenças fundamentais em sua conceituação.

O princípio fornece carga axiológica na interpretação do Direito, não regula situações concretas, mas abstratas, pode ou não estar previsto explicitamente no texto constitucional, mesmo assim é dotado de validade positiva. Outrossim, os princípios não se relacionam a uma situação específica, de maneira que sua interpretação não leva a cabo uma consequência jurídica imediata, mas sim futura.

Segundo WILLIS SANTIAGO GUERRA FILHO” os princípios “[...] devem ser entendidos como indicadores de uma opção pelo favorecimento de determinado valor $[\ldots] "$.

Por seu turno as regras regulam situações concretas, podem estar previstas no texto constitucional ou não, comumente prevêem uma consequência jurídica imediata a uma situação específica.

Assim, para se estabelecer a diferença entre regras e princípios existem diversas formas: ROBERT ALEXY ${ }^{8}$ disserta que "[...] é utilizado com mais frequência é o da generalidade.", o que significa dizer que os princípios possuem nível de generalidade

\footnotetext{
${ }^{7}$ Teoria Processual da Constituição, p.9.

${ }^{8}$ Teoria dos Direitos Fundamentais, p.87. http://revistasapereaude.org/index.php/edicoes/ano-5-volume-2-setembro-2016

D.O.I: 10.20523/sapereaude-ano5-vol-2-pg-64-79
} 
bastante alto, ao passo que as regras, possuem generalidade baixa ou relativa. Outra diferença citada por ROBERT ALEXY ${ }^{9}$ diz respeito à relação de conteúdo para continente entre o princípio e a regra, ou seja, o princípio orienta a regra, fornecendo razões para sua existência e validade jurídica.

A grande problemática a respeito deste tema está relacionada aos conflitos entre as espécies de normas, isto é, os conflitos entre regras e princípios. Nesta situação de conflito é possível obter com maior clareza suas diferenças.

Conquanto o tema suscite inúmeras discussões de valioso conteúdo acadêmico, nos deteremos - por ser o foco do presente estudo - na colisão de princípios de ordem constitucional, especialmente, a colisão entre o princípio constitucional que protege a intimidade e a dignidade da pessoa humana e o direito à segurança como direito fundamental, colisão essa que trás à baila a necessidade do equilíbrio entre o binômio eficiência e garantismo.

Em havendo colisão ou choque de princípios constitucionais, o princípio da proporcionalidade será responsável pela solução do conflito, elegendo, no caso concreto, qual princípio irá prevalecer.

Porquanto, não se delineou ainda como a proporcionalidade irá definir qual princípio deverá prevalecer, ou seja, prevalece o direito à segurança ou o direito à intimidade, liberdade, englobados na dignidade da pessoa humana.

A partir desta dialética surgem duas teses a respeito do assunto, a tese comunitarista e a individualista.

Pela tese comunitarista, significa dizer que em qualquer espécie de colisão entre princípios constitucionais, prevalecerá aquele que atingir o interesse da coletividade. Referida posição é de difícil aceitação, mesmo porque estaria muito próxima a regimes totalitários, no qual as decisões do Estado são sempre fundamentadas no bem da coletividade.

JOÃO PAULO BALTAZAR JÚNIOR ${ }^{10}$ posiciona-se contra a tese comunitarista, na medida em que tal posição legitimaria, a priori, “[...] até mesmo a existência de uma presunção de liberdade (in dubio pro libertate), de modo que não haveria uma regra geral de interpretação dos direitos fundamentais nesse sentido."

\footnotetext{
${ }^{9}$ Ibidem, p. 89.

${ }^{10}$ Crime Organizado e Proibição de Insuficiência, p.206. http://revistasapereaude.org/index.php/edicoes/ano-5-volume-2-setembro-2016

D.O.I: 10.20523/sapereaude-ano5-vol-2-pg-64-79
} 
Por outro lado, a tese individualista afirma sempre a prevalência pelo interesse individual sobre o coletivo, dando razão à leitura subjetiva dos direitos fundamentais, sobretudo, ao princípio da proibição do excesso.

Esta posição tem como supedâneo a origem dos direitos fundamentais, os quais foram concebidos como direitos e garantias dos cidadãos frente ao arbítrio do Estado, o qual num passado não muito distante violava a dignidade da pessoa humana, apresentando como justificativa a manutenção do bem comum.

Ocorre que esta posição nos dias atuais deve sofrer uma releitura. Concordamos que a dignidade da pessoa humana deva prevalecer, a princípio, quando em colisão com os demais direitos fundamentais.

Entretanto, deve-se destacar que ao lado dos direitos conferidos às pessoas há, igualmente, suas obrigações junto à sociedade.

A interpretação da tese individualista permite ao indivíduo ter uma posição, absolutamente, egoísta e descompromissada com os demais membros da sociedade.

Entendendo pela prevalência da dignidade da pessoa humana, em sua leitura individualista, frente a princípios de ordem coletiva, significa dizer que existiria um princípio absoluto, por seu turno, este princípio absoluto conflitaria com outros princípios absolutos da coletividade, analisando cada pessoa, individualmente, as quais veriam seus direitos serem lesionados em benefício da individualidade de outrem.

Em virtude dos argumentos acima destacados comungamos do entendimento que afere primazia inicial à dignidade da pessoa humana, com leitura na individualidade, contudo, apenas primazia inicial. Caberá ao Estado demonstrar, através da aplicação da proporcionalidade, que a dignidade da pessoa humana deverá ceder, no caso concreto, em favor da coletividade ${ }^{11}$.

Estabelecidas essas premissas, encontramos argumentos jurídicos sólidos para a fundamentação da prova ilícita pro reo e também pro societate, conforme fundamenta ANTONIO SCARANCE FERNANDES ${ }^{12}$.

Em sua obra ele analisa dois exemplos claros e em sentido diametralmente opostos, no qual ambas as modalidades foram admitidas: o primeiro exemplo seria relacionado à obtenção, por parte do réu, de uma prova ilícita mediante interceptação telefônica, prova essa que seria cabal para demonstrar sua inocência, vale dizer, sem ela

\footnotetext{
${ }^{11}$ Ibidem, p. 211.

${ }^{12}$ Processo Penal Constitucional, p.84-85. http://revistasapereaude.org/index.php/edicoes/ano-5-volume-2-setembro-2016 
o réu seria condenado a uma pena injusta, dito de outro modo, referida prova ilícita demonstraria que ele não foi o autor do fato que a ele seria imputado, nesse caso, obviamente, a prova ilícita deve ser aceita, inclusive o próprio Supremo Tribunal Federal já se posicionou a favor nesse sentido (STF, HC 74.678-1/SP, 1a Turma, Rel. Min. Moreira Alves, votação unânime, DJ 15/07/1997); o exemplo oposto diz respeito à abertura de correspondências no âmbito do sistema prisional, visando com essa medida evitar a fuga de presos considerados perigosos, na qual se descobriu um plano para assassinar um Juiz de Direito, pela interpretação do texto constitucional tal prova seria de todo ilícita, por violação a norma constitucional, porém, sabiamente o Supremo Tribunal Federal posicionou-se pela admissão da prova em favor da sociedade (STF, HC 70.814-5, Rel. Min. Celso de Mello, DJ 24/06/1994).

A aplicação escorreita do princípio da proporcionalidade permite uma interpretação constitucional coerente com os valores e fundamentos estabelecidos na Carta Política de 1988, tendo como norte sempre o Estado Democrático de Direito com base na dignidade da pessoa humana, conforme preleciona ANTONIO SCARANCE FERNANDES ${ }^{13}$ :

Em suma, a norma constitucional que veda a utilização no processo de prova obtida por meio ilícito deve ser analisada sob à luz do princípio da proporcionalidade, devendo o juiz, em cada caso, sopesar se outra norma, também constitucional, de ordem processual ou material, não supera em valor aquela que estaria sendo violada.

\section{Escutas Telefônicas;}

Serão feitas algumas considerações sobre esse valioso instrumento de investigação, tanto de ordem prática, sob o ponto de vista de como ela é materializada, como também sobre sua utilização como meio de prova no processo penal.

A interceptação telefônica é regida pela Lei 9296/96 a qual regulamenta em quais casos tal meio de prova poderá ser utilizado. Referido ato normativo disciplina toda sua metodologia e como materializar-se-á a prova obtida por esse meio tão importante de produção probatória.

\footnotetext{
${ }^{13}$ Ibidem, p.85.

http://revistasapereaude.org/index.php/edicoes/ano-5-volume-2-setembro-2016

D.O.I: 10.20523/sapereaude-ano5-vol-2-pg-64-79
} 
O tema é extenso, por isso faremos um recorte para delimitação do seu estudo; o recorte feito será na delimitação de casos relacionados à criminalidade organizada.

Dentro do contexto de técnicas especiais de investigação, o monitoramento telefônico é ferramenta fundamental para qualquer tipo de investigação relacionada ao enfrentamento da criminalidade organizada. É uma ilusão acreditar que é possível desmantelar uma organização criminosa sem essa ferramenta.

$\mathrm{Na}$ verdade, também devemos ser coerentes e não depositar toda a confiança apenas e tão somente no monitoramento telefônico, mas sim ao conjunto de mecanismos agora disciplinados pela Lei 12.850/2013.

A interceptação telefônica, atualmente, muito mais serve como norte à Autoridade Policial encarregada de uma investigação, norte esse no sentido de saber aonde, como e o porquê tal prova precisa ser colhida.

Através da análise dos diálogos monitorados é possível estabelecer o perfil criminológico do investigado e identificar sua rede de contatos, pois mediante esse dado é possível aferir qual a extensão do grupo que está sendo investigado.

Não somente a extensão do grupo, mas de que maneira ele afeta bens jurídicos tutelados pela norma penal.

O monitoramento telefônico permite materializar as condutas investigadas no curso da investigação, materialização essa realizada com a utilização de outras provas, sejam elas típicas ou atípicas, que necessitem ou não de chancela judicial para sua obtenção.

Destaque-se que a Polícia Federal, em que pese o respeito pelas outras forças policiais do Brasil, assumiu o protagonismo em metodologia de investigações relacionadas ao enfrentamento à criminalidade organizada; protagonismo esse realizado mediante a provocação junto aos Juízes de primeira instância e de Tribunais Superiores, ao apresentar provas atípicas que jamais tinham sido utilizados dentro do panorama jurídico nacional.

Como provas atípicas temos: a busca exploratória, a instalação de equipamentos para escuta ambiental, a interceptação de fluxo telemático e etc., provas essas já reconhecidas pelos tribunais superiores como válidas dentro do processo.

A despeito de tais considerações, façamos aqui mais um pequeno recorte: as provas descritas nesse pequeno parágrafo são extremamente agressivas, mas dentro do contexto investigatório coube à Autoridade Policial demonstrar ao Juiz e ao Ministério http://revistasapereaude.org/index.php/edicoes/ano-5-volume-2-setembro-2016 
Público que sem esse meio de prova, não seria possível desmantelar o grupo que se investigava, dito de outro modo, sem essas provas - que não são ilícitas, frise-se - não seria possível avançar na investigação.

Porquanto, coube ao Poder Judiciário realizar a aplicação do princípio da proporcionalidade, através de suas balizas, e pender, nesse momento, para a tese comunitarista, como mencionamos acima.

Pois bem, voltemos ao nosso tópico.

A própria interceptação telefônica era utilizada para casos simples, menos complexos. No entanto, a Polícia Federal, no início dos anos 2000 passou a utilizá-la em conjunto com a ação controlada, prevista na antiga Lei 9034/95 como mecanismo que possibilitasse à Autoridade Policial observar o teatro criminoso, observação essa que permitia identificar toda a rede de relacionamentos, extensão, forma e maneira de atuar de um grupo criminoso, deflagrando o cumprimento de medidas constritivas de liberdade no momento mais oportuno sob o ponto de vista de produção probatória, visando identificar o efetivo capo dos grupos organizados.

Obviamente, que no início houve alguns equívocos práticos e operacionais que foram corrigidos pelo Poder Judiciário, de modo que a Polícia Federal teve que se adequar ao que a jurisprudência estava determinando.

Como exemplo, citamos: a necessidade transcrição de diálogos e não apenas a utilização de ementas, a demonstração de que outros meios de prova são inábeis para demonstrar os fatos, a própria duração da interceptação telefônica, a obtenção de dados cadastrais de interlocutores que dialogavam com pessoas monitoradas, bem como a obtenção de extratos de telefônicos de terceiros que dialogavam com números interceptados e etc.

Não comungamos com a utilização desproporcional da interceptação telefônica, comungamos da opinião no sentido de que ela deve ser utilizada e defendida como meio de obtenção, disponível ao Estado, de prova em casos em que outras provas se mostram ineficazes para a consecução de seu objetivo.

\section{Infiltração de Agentes;}


A infiltração policial consiste em meio de prova excepcional, permitido pela Lei 12.850/13, nos arts. 10 a 14, estando, portanto, no rol das mencionadas técnicas de investigação especiais aplicadas no enfrentamento à criminalidade organizada.

Consiste a infiltração no ingresso por policial em organização criminosa, de maneira velada, mediante a utilização de identidade falsa fornecida pelo Estado, com a finalidade de obter informações e provas a respeito da forma de atuação, integrantes, líderes dentre outros.

É preciso dar a devida importância e credibilidade à prova obtida através da infiltração, na medida em que as informações coletadas são provenientes, quando bem empregadas, do âmago da organização. Provas e informações deste nível são, demasiadamente, difíceis de serem obtidas, haja vista as complexas redes de ramificações de um grupo organizado, bem como sua intrincada rede de relacionamentos.

No Brasil a exemplo de outros países como a Argentina e Espanha, o procedimento de infiltração policial deve ser precedido de fundamentada autorização judicial para sua utilização.

A infiltração é técnica excepcional de investigação, o que significa dizer que somente deve ser utilizada, quando outros meios de prova se demonstrem ineficientes no processo de investigação. Esta análise da viabilidade e implantação da infiltração deve ser feita com bastante seriedade, haja vista os riscos que este meio de prova pode levar.

Os riscos vão desde o vazamento da investigação, risco de vida pessoal e familiar do agente infiltrado e até da própria legalidade da prova, podendo, se mal empregada, contaminar as demais provas obtidas.

\section{Ação Controlada;}

O instituto da ação controlada, anteriormente, previsto na Lei 9.034/95, no art.2 ${ }^{\circ}$, inc.II e agora no art. $8^{\circ}$ e art. $9^{\circ}$ da Lei $12.850 / 13$, cujo conteúdo permite, quando se estiver diante de investigação atinente à criminalidade organizada, postergar a ação policial para momento mais conveniente no que se refere à produção de provas.

A Convenção de Palermo no art.20 do referido diploma legal também fez a previsão expressa do que denominou "entrega vigiada". 
Para ANTONIO SCARANCE FERNANDES ${ }^{14}$ a ação controlada consiste em “[...] permissivo legal adotado nos mais civilizados e democráticos países do mundo, onde por razões históricas estão efetivamente preparados para combater o crime organizado".

A essência do referido dispositivo legal, consiste em permitir ao presidente da investigação, leia-se, Delegado de Polícia de carreira, sob pena de não incorrer em crime de prevaricação, postergar eventual ação ou operação policial ${ }^{15}$, no momento em que as provas estiverem mais sólidas, sobretudo, no que se refere à identificação do maior número de integrantes de um grupo criminoso, sua forma de agir, infiltração no poder público e, se possível, seus líderes.

Trata-se de uma estratégia de investigação bastante eficaz, haja vista que na maioria das vezes os líderes ou capos de grupos organizados não se envolvem na prática direta do delito, utilizando-se de interpostas pessoas para a consecução de seu desiderato, de modo que a ação controlada possibilita, quando bem empregada e em cotejo com outros meios de provas (monitoramento telefônico, telemático, vigilância e etc.) identificar o funcionamento efetivo de um grupo criminoso.

\section{Delação Premiada e valoração da prova.}

Nos dias de hoje é quase um modismo falar em delação premiada, muito provavelmente pela sua ampla divulgação nos autos da conhecida Operação Lava Jato, capitaneada pela Polícia Federal, através da Delegacia de Repressão a Crimes Financeiros do Paraná.

Referida investigação, seguramente, entrará para a história como um dos grandes marcos no combate à corrupção no país; diversos veículos de imprensa já anunciam que, em virtude de grande soma de valores locupletados por grupos empresariais, seria um dos maiores escândalos de corrupção da América Latina, quiçá do mundo.

Mas muito além de um grande escândalo, temos novamente a Polícia Federal provocando o debate na comunidade jurídica e acadêmica sobre esse meio de prova que está muito longe de ser um consenso sobre sua origem, finalidade e aplicação.

\footnotetext{
${ }^{14}$ O conceito de crime organizado na Lei 9034, p. 03.

${ }^{15}$ Por ação ou operação policial entendam-se buscas (local e pessoal), apreensões, prisões e diligências diversas.

http://revistasapereaude.org/index.php/edicoes/ano-5-volume-2-setembro-2016

D.O.I: 10.20523/sapereaude-ano5-vol-2-pg-64-79
} 
Malgrado conheçamos alguns dos responsáveis pela investigação, não temos conhecimento sobre detalhes de tão importante trabalho, tendo apenas uma certeza, a que foi feita sob a égide da Lei e a obediência à Constituição Federal, notadamente, aos preceitos inscritos no art. $5^{\circ}$.

Fato é que, conforme noticia a imprensa, estamos diante de um dos mais sofisticados e complexos esquemas de desvio de recursos públicos, no qual temos a simbiose do poder público ${ }^{16}$ com fortíssimos grupos empresariais que praticamente dominam o mercado brasileiro em sua área de atuação.

Quando falamos em simbiose com o poder público, temos que ampliar o nosso o horizonte e perspectiva de análise, ampliar no sentido de entender qual o nível de informações privilegiadas da qual o referido grupo criminoso organizado pode deter.

Para atuar com a desenvoltura que atuavam, pode-se dizer que tinham certeza da impunidade, certeza porque tinham acesso a informações tanto sobre como o Estado investiga, como também quem estava sendo investigado.

Especificamente no que se refere a "sobre como o Estado investiga", cabem alguns comentários: a prática em investigações relacionadas ao crime organizado tem demonstrado que há sempre um fator de necessidade, ou seja, a presença de elementos ligados à segurança pública. Referidos elementos são necessários para que forneçam uma consultoria aos grupos criminosos de como blindar-se de ações policiais, bem como no fornecimento de informações privilegiadas, especificamente, sobre investigações em andamento.

Apenas esse dado, se analisado de forma isolada, já permite ampliarmos o horizonte acima destacado, isto é, que nesse tipo de investigação é absolutamente irrisório valer-se de mecanismos comuns de investigação.

É absolutamente necessária a utilização de mecanismos agressivos de busca do dado negado; é fundamental o cotejo de todos os instrumentos disponíveis na Lei 12.850/13 para o desmantelamento de um grupo criminoso, especialmente, o que esta a se comentar; a utilização conjunta dessas ferramentas permitirá demonstrar ao EstadoJuiz a verdade real que paira sobre os fatos, ou, como sustentado em tópico anterior a verdade possível de ser obtida.

\footnotetext{
${ }^{16}$ Leia-se de maneira mais ampla possível, não apenas a administração pública representada pelo Executivo, mas também com a participação intensa do Poder Legislativo; http://revistasapereaude.org/index.php/edicoes/ano-5-volume-2-setembro-2016 
Em havendo manifestação do acusado em auxiliar as autoridades, as informações por ele fornecidas devem ser analisadas com extrema seriedade, haja vista que ele pode induzir ou mesmo levar a erro as autoridades encarregadas da investigação, com o fito de obter o benefício de redução de sua pena, quiçá o perdão judicial.

Finalmente, pese a eficiência do instituto, comprovadamente utilizada em países de primeiro mundo, há posicionamento doutrinário no sentido de que a utilização da delação estaria eivada de imoralidade, na medida em que incentivaria a traição entre os membros da organização. Logo, o Estado não poderia valer-se deste meio de prova por ser considerado aético e imoral.

A despeito das inúmeras posições a respeito da suposta imoralidade e a ausência de ética no instituto da delação premiada, ousamos pensar de maneira distinta. Aético ou imoral é, justamente, aquele que pratica o crime, sobretudo, quando comprovado seu envolvimento na criminalidade organizada, de extrema gravidade, danosa e nociva à sociedade.

Portanto, se ao delator for conveniente a delação, desde que preenchidos os requisitos legais, respaldado ainda no respeito à sua dignidade, conforme determina a Constituição Federal, entendemos, perfeitamente cabível ao Estado utilizá-la como mecanismo de enfrentamento à criminalidade organizada, despindo-se de ilações filosóficas neste sentido.

Em nosso entendimento o delator, quando auxilia as instituições responsáveis pela persecutio criminis demonstra sim, ética e moralidade, na medida em que o resultado final de sua delação poderá contribuir para condições melhores de vida em sociedade.

\section{REFERÊNCIAS BIBLIOGRÁFICAS:}

ALEXY, Robert. Teoria dos Direitos Fundamentais: tradução Virgílio Afonso da Silva. São Paulo: Editora Malheiros, 2008.

FERnANDES, Antonio Scarance. Provas no Processo Penal, Estudo Comparado. São Paulo: Editora Saraiva, 2011.

Boletim IBCCRIM. São Paulo, n.31, p. 03, jul. 1995.

O conceito de crime organizado na Lei 9034.

http://revistasapereaude.org/index.php/edicoes/ano-5-volume-2-setembro-2016

D.O.I: 10.20523/sapereaude-ano5-vol-2-pg-64-79 
Editora Saraiva, 6ª Edição.2010.

Processo Penal Constitucional. São Paulo:

Organizado. In: Crime Organizado, Aspectos Processuais, Coordenação Antônio Scarance Fernandes, José Raul Gavião de Almeida e Maurício Zanoide de Moraes. São Paulo: Editora Revista dos Tribunais, 2009

FILHO, Willis Santiago Guerra. Teoria Processual da Constituição. $3^{\text {a }}$ Edição. São Paulo: Editora RCS, 2007.

JUNIOR, João Paulo Baltazar. Limites Constitucionais á Investigação. O conflito entre o direito fundamental à segurança e o direto de liberdade no âmbito da investigação criminal. In: Limites Constitucionais da Investigação. Coordenação Rogério Sanches Cunha, Pedro Taques e Luiz Flávio Gomes. São Paulo, Editora Revista dos Tribunais: 2009.

Crime Organizado e Proibição de Insuficiência. Porto Alegre: Editora Livraria do Advogado, 2010.

KERR, Vera Kaiser Sanchez. Provas no Processo Penal, Estudo Comparado. São Paulo: Editora Saraiva, 2011.

SANCTIS, Fausto Martin de. Crime Organizado e Lavagem de Dinheiro. São Paulo: Editora Saraiva, 2009.

SILVA, Marco Antonio Marques; FREITAS, Jayme Walmer de Freitas. Código de Processo Penal Comentado. São Paulo: Editora Saraiva, 2012. 